\title{
MODIFICATION OF CHRONOTROPIC RESPONSE TO ANTICHOLINERGICS BY HALOGENATED ANAESTHETICS IN CHILDREN
}

\author{
Satwant K. Samra and Peter J. Cohen
}

\begin{abstract}
Cardiac rate and rhythm changes were studied in 40 children after intravenous injection of atropine or glycupyrrolate following induction of anaesthesia with halothane and enflurane. Premedication was standardized in all groups and ventilation controlled to achieve normal end tidal carbon dioxide. Heart rate increased in all cases following anticholinergic medication and the increase in heart rate was significantly higher in children receiving halothane anaesthesia as compared to those given enflurane. There was no significant difference between atropine and glycopyrrolate groups. There was no difference in frequency of occurrence of junctional tachycardia, which was the only arrhythmia observed, in the four groups studied. Our findings suggest that, in clinical situations where development of marked tachycardia is a concern, the combination of enflurane and anticholinergic drugs offers an advantage over the combination of halothane and anticholinergic drugs in paediatric patients.
\end{abstract}

ATROPINE HAS BEEN USED as a part of premedication for general anaesthesia for more than a hundred years. Its antisialogogue effect offered distinct advantages when ether was the principal anaesthetic used. Since halothane, enflurane and nitrous oxide do not increase salivary and tracheobronchial secretions to any great extent, many anaesthetists have stopped using atropine as a part of routine premedication in adults. However, it is still customary to use anticholinergic medication in paediatric patients to prevent bradycardia which may be associated with use of halothane or succinylcholine. There have been many studies reporting development of arrhythmias when intravenous atropine or glycopyrrolate is used during halothane anaesthesia ${ }^{1-4}$ but not much has been reported on the use of anticholinergic medication during enflurane anaesthesia in children.

The present study was undertaken to compare changes in cardiac rate and rhythm in children following intravenous injection of atropine or glycopyrrolate after induction of anaesthesia with halothane or enflurane. No effort was made to study the interaction of succinylcholine with these drugs. This study is a report of clinical observations and was not designed to ascertain the mechanism of action of the various drugs.

\section{Methods}

The study was conducted in 40 children be-

Satwant K. Samra, M.D., Instructor in Anesthesiology; Peter J. Cohen, M.D., Professor and Chairman, Department of Anesthesiology, University of Michigan Medical Center. tween six months and twelve years of age who were scheduled for elective operations. All children were free of cardiac or respiratory disease and were classed as A.S.A. Physical Status 1. These patients were assigned randomly to one of the following groups:

Group I - injection of atropine after induction with halothane

Group II - injection of glycopyrrolate after induction with halothane

Group III - injection of atropine after induction with enflurane

Group IV - injection of glycopyrrolate after induction with enflune.

Each group consisted of ten patients. Induction of anaesthesia in all cases was carried out under the supervision of same staff anaesthetist (SKS) by different resident physicians or nurse anaesthetists.

All children were premedicated with morphine sulphate $0.1 \mathrm{mg} \cdot \mathrm{kg}^{-1}$ and secobaritone $2 \mathrm{mg} \cdot \mathrm{kg}^{-1}$ intramuscularly, approximately one hour before coming to the operating room. Induction of anaesthesia was carried out by inhalation of a mixture of 60 per cent nitrous oxide with oxygen and either enflurane or halothane. The halogenated agents were administered either through a calibrated enfurane vaporizer (Ohio Medical Products) or a Fluotec Mark Il Vaporizer.

After induction, measurement of end tidal carbon dioxide was approximated by placing an 18gauge Angiocath ${ }^{B}$ connected to the heated sample inlet tube of a Beckman Medical Gas Analyzer L.B. II under a tight-fitting face mask. Ventilation was controlled whenever necessary 
TABLE I

Distribution of Patients According to Age, Sex and Weight $(\mathrm{MEAN} \pm \mathrm{SE})$

\begin{tabular}{ccccc}
\hline \hline & & \multicolumn{2}{c}{ Sex } & \\
\cline { 3 - 4 } Group & $\begin{array}{c}\text { Age (years) } \\
\text { (mean } \pm \text { SE) }\end{array}$ & Male & Female & $\begin{array}{c}\text { Weight (kg) } \\
\text { (mean } \pm \text { SE) }\end{array}$ \\
\hline I (H.A.) & $3.1 \pm 0.7^{*}$ & 5 & 5 & $14.8 \pm 2.2$ \\
II (H.G.) & $6.3 \pm 0.8$ & 4 & 6 & $18.2 \pm 1.5$ \\
III (E.A.) & $4.7 \pm 0.8$ & 4 & 6 & $18.3 \pm 1.9$ \\
IV (E.G.) & $4.3 \pm 0.7$ & 7 & 3 & $17.9 \pm 1.8$ \\
\hline
\end{tabular}

*I and II differ significantly $(p<0.05)$.

TABLE II

Comparison of Time Intervals in Minutes (Mean \pm SEM)

\begin{tabular}{cccc}
\hline \hline & $\begin{array}{c}\text { Premedication to } \\
\text { start of induction }\end{array}$ & $\begin{array}{c}\text { Start to end of } \\
\text { induction }\end{array}$ & $\begin{array}{c}\text { Start of induction } \\
\text { to injection of } \\
\text { anticholinergic drug }\end{array}$ \\
\hline I (H.A.) & $60.9 \pm 8.8$ & $5.5 \pm 1.1$ & $12.1 \pm 1.8$ \\
II (H.G.) & $77.1 \pm 9.2$ & $5.5 \pm 0.8$ & $11.1 \pm 1.8$ \\
III (E.A.) & $86.7 \pm 11.9$ & $5.4 \pm 0.3$ & $11.5 \pm 1.3$ \\
IV (E.G.) & $72.7 \pm 8.5$ & $5.0 \pm 0.4$ & $11.4 \pm 2.7$ \\
\hline
\end{tabular}

until end tidal carbon dioxide was between 4.5 to 5.5 volumes per cent.

The electrocardiogram (EKG) (Lead II) was monitored and recorded during this time and blood pressure and heart rate were recorded. Glycopyrrolate in a dose of $0.005 \mathrm{mg} \cdot \mathrm{kg}^{-1}$ or atropine $0.01 \mathrm{mg} \cdot \mathrm{kg}^{-1}$ was then given intravenously and the EKG was recorded continuously for five minutes thereafter. The choice of these doses was based on previous studies ${ }^{5.6}$ recammending that the dose of glycopyrrolate be half that of atropine. Changes in blood pressure, heart rate and rhythm were recorded. The EKG tracings were interpreted at a later date by a cardiologist who was unaware of the drugs used.

The following data were recorded: age, sex, weight, time interval between premedication and start of induction of anaesthesia, time from start to end of induction, and time from beginning of induction until injection of anticholinergic drugs.

The delivered concentration of halothane or enflurane was noted during induction and at the time of injection of anticholinergic drugs. A constant concentration of halogenated agent was delivered for seven to eight minutes in each case before the anticholinergic drug was injected. Changes in heart rate and systolic blood pressure or any arrhythmia after injection of anticholinergic drugs were recorded.

Numerical data for all four groups were sub- jected to analysis of variance. When this test was significant $(\mathrm{p}<0.05$ ), specific differences between groups were sought using Student's t-test for unpaired data. Chi-square analysis was used to compare the incidence of arrhythmias in the four groups.

\section{RESULTS}

Table I presents the mean age and weight of four groups studied. The mean age of children in Group I was significantly lower than those in Group Il while the mean weight was not significantly different. When the mean age of all children receiving halothane anaesthesia (Groups I and II) was compared with that of all children given enflurane anaesthesia (Groups III and IV) there was no significant difference. To determine the effect of age on increase in heart rate the data were subjected to an analysis of co-variance (Netter and Wasserman, 1974), ${ }^{7}$ using age as a co-variate, anaesthetic technique being an independent variable and increase in heart rate the dependent variable. The relationship between change in heart rate and age was not statistically significant.

There were no significant differences in time interval between premedication and induction of anaesthesia, speed of induction and duration of inhalation of halogenated agents before injection of anticholinergic drugs (Table II). 
TABLE III

Changeg in Heart Rate (Mean \pm SEM) BEATS/MIN

\begin{tabular}{lcc}
\hline Group & Baseline & Increase \\
\hline I (H.A.) & $92 \pm 4.2$ & $35.2 \pm 4.9$ \\
II (H.G.) & $84 \pm 3.3$ & $45.2 \pm 4.1$ \\
III (E.A.) & $92 \pm 6.0$ & $15.8 \pm 4.5$ \\
IV (E.G.) & $99 \pm 4.1$ & $21.0 \pm 3.1$ \\
Significance & N.S. & $*$ \\
\hline *I vs III - significant $p<0.005$. \\
II vs IV - significant $p<0.001$. \\
I and II vs III and IV - significant $p<$ \\
0.001.
\end{tabular}
0.001 .

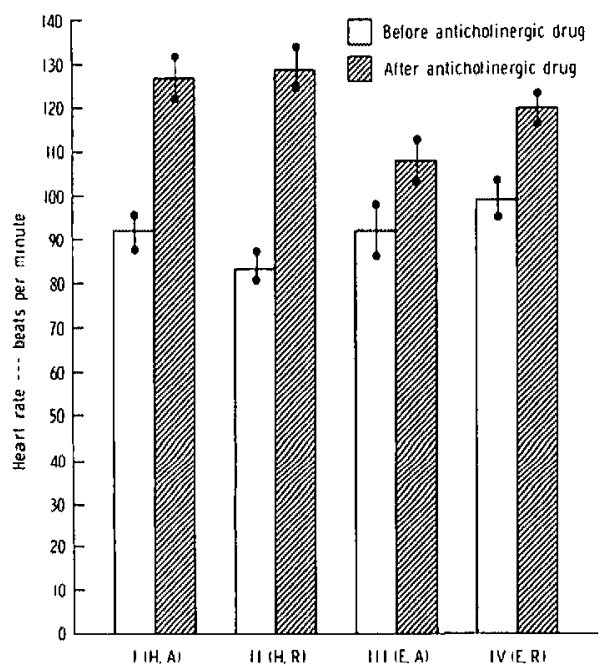

Figure1 Changes in heart rate after anticholinergic drugs (mean \pm S.E.). Statistical Analyses: Base line heart rate no significant difference, $H$. A vs $E$. A -significant $p<0.05$. H. R vs E. R - significant $p<0.05$.

Table III and Figure 1 summarize the changes in heart rate after injection of atropine or glycopyrrolate. Although mean heart rate before injection of anticholinergic (baseline heart rate) in Group II appeared to be slightly lower than others, this difference was not statistically significant. However, the increase in heart rate in Groups I and II was significantly higher than that in Groups III and IV. The change in systolic blood pressure that accompanied the rise in heart rate was insignificant. When Groups I and II were compared the differences were not significant and the same was true of a comparison of Groups III and IV.

Table IV summarizes the electrocardiographic
TABLE IV

Electrocardiographic Changes

\begin{tabular}{ccc}
\hline \hline Group & Junctional rhythm & No change \\
\hline I (H.A.) & 6 & 4 \\
II (H.G.) & 4 & 6 \\
III (E.A.) & 3 & 7 \\
IV (E.G.) & 4 & 6 \\
\hline
\end{tabular}

changes. No change in rhythm was noted in 23 out of 40 cases. The only abnormality of rhythm was development of junctional tachycardia in 17 cases. This arrhythmia was not associated with any change in blood pressure and changed back spontaneously to sinus rhythm within four minutes in all except two cases in which it lasted eight to nine minutes. Both patients were receiving halothane anaesthesia. Junctional rhythm developed in six out of ten in Group I; four out of ten in Groups II and IV, and three out of ten patients in Group III. This difference was not of statistical significance. No ventricular arrhythmias were noted in this study.

Table V shows the time intervals between injection of anticholinergic drug and development of junctional tachycardia in 14 patients in whom this tachyarrhythmia followed anticholinergic medication. This time interval was much shorter (mean 36 seconds) in patients anaesthetized with halothane (Groups I and II) as compared to those under enflurane anaesthesia (mean 151 seconds). This difference was statistically significant.

Concentrations of halogenated anaesthetics delivered during induction were not significantly different (Table VI). However, when concentrations were expressed as MAC fraction, taking adult MAC halothane $=0.77$ per cent ${ }^{8}$ and MAC enflurane $=1.68,{ }^{9}$ it was noted that the anaesthetic potency in Groups I and II may have been significantly higher than that in Groups III and IV. All children were judged clinically to be sufficiently anaesthetized to proceed with tracheal intubation. Conversion of delivered concentrations of halothane and enflurane to MAC fraction was used only to compare the potency of two anaesthetic drugs.

It is generally believed that, compared to adults, children require higher concentrations of halothane for a given effect. Halothane has been reported to be 1.12 times more potent in producing anaesthesia in adults than in children 6 to 24 months of age. ${ }^{10}$ Similar data for potency of enflurane in children compared to adults are not available. 
TABLE $\mathrm{V}$

Relationship of ONSET of Junctional Tachycardia to InJection of ANTicholinergic Drug

\begin{tabular}{lcccc}
\hline \hline \multirow{2}{*}{ Under halothane anaesthesia } & & \multicolumn{2}{c}{ Under enflurane anaesthesia } \\
\cline { 1 - 1 } Name & $\begin{array}{c}\text { Time interval in seconds } \\
\text { after injection }\end{array}$ & & Name & $\begin{array}{c}\text { Time interval in seconds } \\
\text { after injection }\end{array}$ \\
\hline M.J. & 30 & & O.W. & 180 \\
K.Z. & 90 & B.B. & 180 \\
R.S. & 60 & W.R. & 38 \\
H.M. & 14 & R.J. & 60 \\
F.A. & 30 & S.R. & 180 \\
M.M. & 15 & S.B. & 240 \\
M.T. & 16 & E.M. & 180 \\
\hline Mean & 36.4 & & $* 151.1$ \\
SEM & \pm & & & \pm \\
\cline { 1 - 1 } & 9.7 & &
\end{tabular}

*Enflurane vs halothane significant $p<0.05$.

TABLE VI

Concentration of Halogenated Agents $(\mathrm{MEAN} \pm \mathrm{SEM})$

\begin{tabular}{ccc}
\hline \hline Group & Volumes per cent & Mac fraction \\
\hline I (H.A.) & $1.95 \pm 0.13$ & $2.60 \pm 0.18$ \\
II (H.G.) & $1.85 \pm 0.16$ & $2.46 \pm 0.22$ \\
III (E.A.) & $2.59 \pm 0.35$ & $* 1.54 \pm 0.21$ \\
IV (E.G.) & $2.80 \pm 0.39$ & $* 1.66 \pm 0.23$ \\
Significance & N.S. & $*$
\end{tabular}

I vs III - significant $p<0.0008$.

II vs IV - significant $p<0.01$.

In order to make the two groups comparable we modified our protocol in another group of ten patients. In these patients anaesthesia was induced by inhalation of a mixture of 60 per cent nitrous oxide with oxygen and halothane, with concentration maintained at 1.2 per cent $(1.5$ $M A C$ using adult MAC values) for eight to ten minutes. Anticholinergic drug, either atropine $0.01 \mathrm{mg} \cdot \mathrm{kg}^{-1}$ or glycopyrrolate $0.005 \mathrm{mg} \cdot \mathrm{kg}^{-1}$ was then injected. EKG Lead II was recorded for the next five minutes and changes in rate and rhythm were noted. Table VII shows the control heart rate and increase in heart rate after anticholinergic drugs in these additional ten patients. When these data were compared with Groups I and II no significant differences were found either in increase in heart rate or occurrence of junctional tachycardia. When compared with Groups III and IV (enflurane and anticholinergic drugs) the rise in heart rate in these patients was significantly higher. Inclusion of
TABLE VII

Changes in Heart Rate (Mean \pm SEM) Beats/ Min After Halothane 1.25 Per CENT for 8-10 MINUTES

\begin{tabular}{lcc}
\hline Drugs used & Control heart rate & Increase \\
\hline $\begin{array}{l}\text { Halothane and } \\
\text { atropine }\end{array}$ & $87.2 \pm 4.4$ & $32.8 \pm 5.4$ \\
$\begin{array}{l}\text { Halothane and } \\
\text { glycopyrrolate }\end{array}$ & $89.0 \pm 7.3$ & $37.2 \pm 2.6$ \\
\hline
\end{tabular}

these additional patients in Groups I and II also eliminated the difference in mean age of these two groups.

\section{Discussion}

There are many reports of dangerous arrhythmias occurring after intravenous atropine during halothane anaesthesia ${ }^{1-4}$ but only a few studies of heart rate and rhythm after intravenous atropine have been done in a controlled fashion. Because of differences in dose used and surgical procedures the conclusions reached by different authors are at variance.

The purpose of this investigation was to compare the changes in cardiac rate and rhythm following intravenous injection of atropine or glycopyrrolate in commonly used dosages during halothane anaesthesia with those during administration of enflurane. Premedication was standardized to make the groups comparable. It can be argued that secobarbitone and morphine used fc- premedication in this study might have an 
effect on reactivity of the autonomic nervous system, but there is no evidence that this effect would differ among the four groups studied. Ventilation was controlled during induction to prevent development of hypercarbia.

In the present study the only arrhythmia noted was junctional tachycardia, which followed injection of anticholinergic drugs. We did not find any significant differences in frequency of rhythm disturbances among the four groups studied. Development of supraventricular tachycardia after intravenous use of anticholinergics is in keeping with previously reported studies. ${ }^{1,2,11.12}$ None of the EKG abnormalities in our study lead to serious ventricular arrhythmias as noted in some of the previous studies. ${ }^{1,3,4}$ No consistent changes in arterial pressure were observed as a result of arrhythmias or change in heart rate.

There have been claims that glycopyrrolate is associated with a lower incidence. of dysrhythmias. ${ }^{13}$ Our findings fail to support this claim as there was no significant difference in development of junctional tachycardia in patients receiving atropine (Groups I and III) or glycopyrrolate (Groups II and IV). These findings are similar to those of Wong and others ${ }^{14}$ who compared glycopyrrolate as a substitute for atropine in reversal of curarisation in paediatric patients and did not find glycopyrrolate to be less arrhythmogenic. We also failed to find a significant difference in heart rate between atropine and glycopyrrolate groups as reported by some investigators. ${ }^{6.13 .15}$

In a double blind study comparing the usefulness of glycopyrrolate with atropine as a premedicant (given intravenously $45-60$ minutes before induction) and given intravenously to antagonize the muscarinic effect of neostigmine methylsulphate given to reverse neuromuscular blockade, Oduro ${ }^{16}$ concluded that there was no difference in changes in pulse rate following intramuscular injection of the two drugs. Following intravenous administration at two minutes the glycopyrrolate group exhibited a lesser degree of tachycardia; however, by the five-minute observation it appeared that glycopyrrolate was associated with a greater increase in heart rate. In our study we compared the peak increase in heart rate after five minutes. Our findings are similar to those of Oduro in that patients who received glycopyrrolate under both halothane and enflurane anaesthesia showed greater increase in hear rate. However, there was no statistically significant difference when compared with those receiving atropine.
In our study the increase in heart rate in patients under halothane anaesthesia was nearly twice the increase seen in patients under enflurane anaesthesia. Jones, Deutsch and Turndorf ${ }^{17}$ studied the effect of atropine on cardiac rhythm in conscious and anaesthetized man and documented that the accelerating effect of atropine on heart rate appears to be enhanced during anaesthesia. Munchow and Denson ${ }^{18}$ demonstrated that halothane - nitrous oxide anaesthesia increased the chronotropic action of atropine. Our findings of marked positive chronotropic effect under anaesthesia are in keeping with their observations. A significant increase in heart rate following anticholinergic drugs in patients under halothane compared to those under enflurane anaesthesia may reflect differences in effect of the two anaesthetics on vagal tone. Price, Linde and Morse ${ }^{19}$ studied the central nervous system actions of halothane affecting the systemic circulation and suggested that halothane increases vagal tone.

It can be questioned whether a significant difference in age between Groups I and II could influence our results. Dauchot and Gravenstein ${ }^{20}$ have reported that atropine has less effect on heart rate in young children. Accordingly, if the mean ages of Groups I and II were comparable we might have seen greater increase in heart rate in Group I. This part of the study was essentially repeated in the Group of patients who received either atropine or glycopyrrolate after 1.25 per cent of halothane. Mean age of children given atropine was 6.5 years and those given glycopyrrolate was 5.5 years. There was no significant difference either in control heart rate or in increase in heart rate (Table VII) in these two groups. The significant finding in this study is not the difference in chronotropic response to atropine or glycopyrrolate but the marked difference in tachycardia developing under halothane compared to enfiurane anaesthesia. Mean age of all children given halothane (Groups I and II) was not different from those receiving enflurane (Groups III and IV). Therefore, age is not likely to have influenced this observation.

Our observation that there was no significant difference in control heart rates (before given anticholinergic) or increase in heart rates (following injection of anticholinergic drugs) among patients breathing halothane 1.2 per cent and those breathing halothane two per cent agrees with findings of Farman ${ }^{21}$ who studied the circulatory response to intravenous injection of atropine $0.6 \mathrm{mg}$ during nitrous oxide-oxygen and 
halothane anaesthesia. The concentration of halothane in his study varied from 0.5 to 2.0 per cent from a Fluotec vaporizer, mixed with nitrous oxide 60 per cent and oxygen. He reported no significant difference in initial heart rate or change of heart rate among patients on different concentrations of halothane.

On the basis of this study we conclude that atropine and/or glycopyrrolate can be safely given intravenously to paediatric patients under halothane and enflurane anaesthesia. Administration of these drugs in doses used in this study is not a cause of dangerous arrhythmias in healthy children. We also found that anticholinergic drugs give rise to a greater degree of tachycardia during halothane anaesthesia as compared to enflurane. This finding has not been reported before and the exact mechanism of this effect remains to be elucidated.

\section{REFERENCES}

1. Eger, E.I. Atropine, scopolamine and related compounds. Anesthesiology 23: 365 (1962).

2. Thurlow, A.C. Cardiac dysrhythmias in outpatient dental anaesthesia in children. Anaesthesia 27: 429 (1972).

3. ZiPes, D.P. \& KNoebel, S.B. Rapid rate dependent ventricular ectopy. Chest $2: 255$ (1972).

4. Kiм, J.W. \& SмiтH, P.N. Cardiac dysrhythmia after intravenous glycopyrrolate in anesthetized man. Anesthesiology Review 5: 30 (1978).

5. RamamuRThy, S., Ylagan, L.B.\& Winnie, A.P. Glycopyrrolate as a substitute for atropine: a preliminary report. Anesthesia \& Analgesia (Cleve) 50:732 (1971).

6. Ostheimer, G.W. A comparison of glycopyrrolate and atropine during reversal of nondepolarizing neuromuscular block with neostigmine. Anesthesia \& Analgesia (Cleve) 56: 182(1977).

7. Neter, J. \& Warkerman, W. Applied linear statistical models. 1st edition. Illinois: Richard D. Irwin, Inc. (1974).

8. Saidman, L.J., Eger, E.I. \& Munson, E.S. Minimum alveolar concentration of methoxyflurane, halothane, ether and cyclopropane in man: correlations with theories of anesthesia. Anesthesiology 28: 994 (1967).

9. Gion, N. \& Saldman, L. The minimum alveolar concentrations of enflurane in man. Anesthesiology $35: 226(1971)$.

10. Nicodemus, N.F., Nassiri-Rahimi, C., BachMAN, L. \& SMITH, T.C. Median effective doses of halothane in adults and children. Anesthesiology 31: 344 (1969).

11. Eikard, B. \& ANoersen, J.R. Arrhythmias during halothane anaesthesia. II. The influence of atropine. ACTA Anaesthesiological Scandinavian 21(3): 245 (1977):

12. Carrow, D.J., Aldrete, J.A., Masden, R.R., ef at. Effects of large doses of intravenous atropine on heart rate and arterial pressure of anesthetized patients. Anesthesia \& Analgesia (Cleve) 54: 262 (1975).

13. WINNIE. A.P. Correspondence. Anesthesiology Review 6: 51 (1977).

14. Wong, A. Y., Salem, M.R., Mani, M. et al. Glycopyrrolate as a substitute for atropine in reversal of curarization in pediatric cardiac patients. Anesthesia \& Analgesia (Cleve) 53:412 (1974),

15. Ramamurthy, S., Ylagan, L.B. \& Winnie, A.P. Glycopyrrolate as a substitute for atropine - a preliminary report. Anesthesia \& Analgesia (Cleve) 50: $732(1971)$

16. ODuro, K.A. Glycopyrrolate methobromide comparison with atropine sulfate in anaesthesia. Canad. Anaesth. Soc. J. 22: 466 (1975).

17. Jones, R. E., Deutsch, S. \& Turndorf, H. Effects of atropine on cardiac rhythm in conscious and anesthetized man. Anesthesiology 22: 67 (1961).

18. Munchow, O.B. \& Denson, J.S. Madification by light cyclopropane and halothane anesthesia of the chronotropic effect of atropine in man. Anesthesia and Analgesia (Cleve) 44(6): 782 (1965).

19. Price, N.L., Linde, W. \& Morse, N.T. Central nervous actions of halothane affecting the systemic circulation. Anesthesiology 24: 770 (1963).

20. Dauchot, P. \& Gravenstein, J.S. Effect of atropine on the electrocardiogram in different age groups. Clinical Pharmacology and Therapeutics 12: $274(1971)$.

21. Farman, J.V. Circulatory effects of atropine during halothane anaesthesia. British Journal of Anaesthesia 39: 226(1967).

\section{RÉSUMÉ}

On a comparé les effets d'une injection d'atropine à ceux du glycopyrrolate sur la fréquence et le rythme cardiaque, chez 40 enfants anesthésiés à l'halothane ou à l'enflurane. En guise de prémédication, les enfants recevaient de la morphine à la dose de $0.1 \mathrm{mg} \cdot \mathrm{kg}^{-1}$ et du sécobarbital à raison de $2 \mathrm{mg} \cdot \mathrm{kg}^{-1}$ par voie intramusculaire, une heure avant l'arrivée en salle d'opération. La ventilation était ajustée de façon à obtenir une $\mathrm{PCO}_{2}$ de fin d'expiration normale.

La fréquence cardiaque s'est élevée dans tous les cas après l'injection de l'agent anticholinergique, et ceci de façon significativement plus élevée chez les enfants anesthésiés à l'halothane que chez ceux ayant reçu de l'enflurane. On n'a pas trouvé de différence significative entre les effets de l'atropine et ceux du glycopyrrolate. On n'a également pas noté de différence dans l'incidence des tachycardies jonctionnelles qui ont constitué les seules arythmies observées. Nos résultats suggèrent. que dans les situations cliniques où une tachycardie importante est à craindre chez l'enfant, l'association enflurane-anticholinergique est préférable à l'association haluthane-anticholinergique. 